\title{
TRABALHADORES COM DEFICIÊNCIA: VIVÊNCIAS DE PRAZER E SOFRIMENTO
}

\author{
TRABAJADORES CON DISCAPACIDAD : EXPERIENCIAS DE PLACER Y \\ SUFRIMIENTO \\ WORKERS WITH IMPAIRMENT: EXPERIENCES OF PLEASURE AND \\ SUFFERING \\ Cecília Martins Coelho \\ Secretaria de Estado de Saúde de Minas Gerais, Belo Horizonte/MG, Brasil \\ Rosana Ferreira Sampaio e Marisa Cotta Mancini \\ Universidade Federal de Minas Gerais, Belo Horizonte/MG, Brasil
}

\begin{abstract}
RESUMO
Pessoas com deficiência foram historicamente segregadas e consideradas incapazes para o trabalho, mas atualmente preconiza-se sua inclusão em uma perspectiva biopsicossocial. Consequentemente, o número de trabalhadores com deficiência aumentou, embora a forma como vivenciam o trabalho ainda seja pouco conhecida. O objetivo deste estudo foi apreender como os trabalhadores com deficiência vivenciam e dão sentido à experiência de trabalho. Foram realizadas 30 entrevistas semiestruturadas. $\mathrm{O}$ trabalho apresentou-se como organizador da vida, estruturador da identidade e gerador de prazer e sofrimento, resultando em atitudes resilientes. O prazer mostrouse relacionado a recompensas pessoais e sociais. $\mathrm{O}$ sofrimento associou-se às imposições e apropriações das exigências organizacionais, individualismo, desvalorização e falta de reconhecimento. Trabalhar com uma deficiência revelou-se uma experiência complexa, que envolve a interação entre um corpo com lesões, a subjetividade do trabalhador, a organização do trabalho e a sociedade como um todo.
\end{abstract}

Palavras-chave: pessoas com deficiência; carga de trabalho; satisfação no emprego; estresse psicológico; narrativas pessoais.

\section{RESUMEN}

Las personas con discapacidad han sido históricamente segregadas y consideradas incapaces de trabajar, pero en la actualidad se recomienda su inclusión en una perspectiva biopsicosocial. En consecuencia, el número de trabajadores con discapacidad ha aumentado, a pesar que la forma como vivencian el trabajo aún es poco conocida. Este estudio trata de comprender cómo estos trabajadores experimentan y dan sentido a la experiencia laboral. Se realizaron 30 entrevistas semi-estructuradas. El trabajo se presenta como organizador de la vida, estructura de la identidad y generador de placer y sufrimiento, lo que resulta en actitudes resilientes. El placer se relaciona con recompensas personales y sociales. El sufrimiento a las exigencias e imposiciones de las organizaciones, individualismo, desvalorización y falta de reconocimiento. Trabajar con una discapacidad ha demostrado ser una experiencia compleja que implica la interacción entre un cuerpo con lesiones, la subjetividad, la organización del trabajo y la sociedad en su conjunto.

Palabras clave: personas con discapacidad; carga de trabajo; satisfacción en el empleo; estrés psicológico, narraciones personales.

\begin{abstract}
People with impairments were historically segregated and perceived as unable to work, but their social inclusion has been lately advocated in a biopsychosocial approach. Therefore, the number of workers with impairments has increased, but there is still little knowledge about the way they experience work. The aim of this study was to apprehend how workers with impairments experience and give meaning to their work. Thirty semi-structured interviews were carried out. The meaning of work was related to life organization, identity structuring and pleasure and suffering development, which resulted in resilient attitudes. Pleasure was related to personal and social rewards. Suffering was associated with the imposition and the appropriation of organizational demands, individualism, devaluation and lack of recognition. Working with an impairment proved to be a complex experience that involved the interaction between a body with impairments, the subjectivity of the worker, the work organization and the society as a whole.
\end{abstract}

Keywords: disabled persons; workload; job satisfaction; psychological stress; personal narratives. 


\section{Introdução}

As categorias deficiência e trabalho têm sido abordadas de distintas formas em cada época, cultura e lugar, em função de valores sociais, morais, filosóficos, éticos e religiosos (Carmo, 1994; Foucault, 2001; Ornellas \& Monteiro, 2006), o que influencia o modo como o trabalhador com deficiência é percebido e tratado na sociedade contemporânea.

Em tempos remotos, a deficiência não era considerada um problema (Aranha, 1995) e o trabalho era visto como uma ação necessária e natural à existência humana (Carmo, 1994). Ao longo dos anos, entretanto, as causas da deficiência passaram a ser atribuídas a motivos místicos e sobrenaturais e a pessoa com deficiência passou a ser vista como aleijada e inválida (Amaral, 1995; Oliveira, Araújo, \& Romagnoli, 2006; Pereira, 2006, Sassaki, 1999), dando início a um extenso processo de discriminação. Como a sociedade tornouse mais urbana e industrial, a capacidade produtiva passou a ser cada vez mais valorizada, o que levou à exclusão de pessoas com deficiência do mercado de trabalho por serem consideradas incapazes de produzir como os outros trabalhadores (Ornellas \& Monteiro, 2006; Pereira, 2006; Sassaki, 1999). Nesse cenário, foi construído um novo discurso sobre deficiência, que passou a ser tratada como um problema individual, e a pessoa com deficiência foi colocada no lugar de doente e dependente de cuidados (Organização Mundial da Saúde - OMS, 2003; Pereira, 2006; Sassaki, 1999).

A deficiência só tornou-se uma questão social com o aumento do número de casos. A maior quantidade de acidentese de deficiências adquiridas após a disseminação da produção em massa, sistematizada e fragmentada, a intensificação do ritmo de trabalho e, ainda, o grande número de pessoas com sequelas decorrentes de guerras tornaram visível a necessidade de se assegurar postos de trabalho para pessoas com deficiência (Antunes, 2006; Aranha, 1995; Ornellas \& Monteiro, 2006). As tentativas iniciais de integração social, apesar de insuficientes para acabar com a discriminação (Pereira, 2006; Sassaki, 1999), possibilitaram a difusão do potencial de trabalho da pessoa com deficiência (Amaral, 1995). Movimentos em defesa dos direitos das minorias constituíram um contraponto ao estigma e ao isolamento (Aranha, 1995), favorecendo o surgimento de novas perspectivas que preconizam que a deficiência é um problema criado socialmente e que, por esse motivo, requer ações sociais para seu enfrentamento (Diniz, 2007; Oliveira, Araújo, \& Romagnoli, 2006).

À medida que foi se estabelecendo como campo de conhecimento, a deficiência passou a ser entendida como uma condição multideterminada, com dimensões físicas, sensoriais, intelectuais, psíquicas e sociais (Aranha, 1995). Foi estabelecido o caráter relacional entre deficiência e incapacidade, sendo ressaltada a importância da condição de saúde e dos fatores ambientais e pessoais nesse processo (OMS, 2003; Sampaio \& Luz, 2009). Apesar de essa discussão estar em pauta, a sociedade ainda tem dificuldades para implementar as mudanças necessárias para efetivamente incluir as pessoas com deficiência no trabalho (Sassaki, 1999). Como argumenta Pereira (2006), as conquistas obtidas em relação à participação da pessoa com deficiência no trabalho foram muitas, mas as mudanças propriamente ditas requerem mais tempo, pois envolvem a transformação de toda a sociedade.

No Brasil, segundo informações obtidas no censo realizado pelo Instituto Brasileiro de Geografia e Estatística (IBGE) no ano 2010, pelo menos 45 milhões de brasileiros possuem algum tipo de deficiência, o que representa $23,9 \%$ do total da população (IBGE, 2011). Poucos estudos, entretanto, têm investigado o trabalho na perspectiva dos trabalhadores com deficiência, independente da causa, tipo e gravidade da lesão. A maneira como essas pessoas vivenciam o trabalho e compartilham suas relações sociais, afetivas e profissionais é aspecto importante no estudo do trabalho, sendo necessário compreender as situações que geram sofrimento para que se possa intervir e transformar (Lancman \& Sznelwar, 2004; Mendes \& Tamayo, 2001; Ramminger \& Nardi, 2008).

O objetivo deste estudo foi apreender como as pessoas com deficiência, inseridas no mercado de trabalho formal e informal da região metropolitana de Belo Horizonte/MG, vivenciam e dão sentido às suas experiências de trabalho.

\section{Métodos}

A partir de uma abordagem qualitativa, foram realizadas 30 entrevistas semiestruturadas e individuais, com pessoas residentes na região metropolitana de Belo Horizonte/MG que exerciam atividade remunerada e possuíam alguma deficiência na perspectiva do modelo biopsicossocial da Organização Mundial de Saúde: perda ou anormalidade de estrutura do corpo ou função fisiológica (OMS, 2003). A amostragem foi por bola-de-neve (Turato, 2003), a partir de indicações dos participantes, profissionais e comunidade; e o tamanho foi definido por saturação, isto é, as entrevistas foram encerradas quando as informações começaram a se repetir (Fontanella, Ricas, \& Turato, 2008). 
A coleta de dados ocorreu no período de fevereiro a junho de 2009, sendo iniciada após aprovação pelo Comitê de Ética em Pesquisa da Universidade Federal de Minas Gerais (Parecer $\mathrm{n}^{\circ}$. ETIC 477/08) e de um estudo piloto para testar o roteiro de entrevista, o que assegurou o seu entendimento pelos entrevistados. Foram coletados dados sociodemográficos, ocupacionais e informações referentes à escolha profissional, rotina de trabalho, dificuldades, estratégias, relacionamento interpessoal, satisfação e significado do trabalho. Os participantes assinaram termo de consentimento livre e esclarecido e, quando a entrevista ocorreu no local de trabalho, os responsáveis pela empresa/instituição assinaram carta de apoio. As entrevistas foram gravadas e transcritas, de forma a recuperar a integralidade das falas, sendo dada oportunidade aos participantes para revisar o texto e fazer alterações. $\mathrm{Na}$ impossibilidade de se estabelecer comunicação oral, a entrevista foi realizada com auxílio de uma intérprete da Língua Brasileira de Sinais, mediante comprometimento quanto ao sigilo das informações. Também foi utilizado diário de campo para registro de observações e anotações relevantes.

A análise de conteúdo foi feita em três etapas: pré-análise (leitura e releitura dos dados), exploração do material (organização do material em unidades temáticas) e tratamento dos resultados obtidos e interpretação (atribuição de significado aos achados a partir da revisão de literatura, ao longo de todo o estudo, de modo a relacionar as categorias encontradas com o corpo de conhecimento existente) (Bardin, 2008). O programa QRS International's NVIVO 8 (QRS International, 2008) foi utilizado para definir as categorias iniciais (free nodes), identificar similaridades e diferenças, fazer anotações, registrar pensamentos, conceitos e procedimentos (memos), estabelecer relações, criar atributos para classificar, identificar padrões, acessar e manipular os dados, recuperar segmentos dos textos, organizar e estruturar os dados hierarquicamente (tree nodes). Os procedimentos de coleta, transcrição e análise das entrevistas foram realizados por uma única pesquisadora.

\section{Resultados e discussão}

A média de idade dos entrevistados foi de 39 anos $(\mathrm{DP}=13)$, sendo metade do sexo feminino, com características diversificadas quanto à escolaridade, estado civil, tipo de deficiência e ocupação (Tabela 1). Das 23 empresas/instituições contratantes, oito eram públicas, duas eram microempresas (até nove funcionários); oito de pequeno porte (10 a 99 funcionários); sete de médio porte (100 a 499 funcionários); e as demais de grande porte.

Tabela 1. Caracterização dos participantes do estudo quanto aos dados sociodemográficos, ocupacionais e relacionados à deficiência

\begin{tabular}{|c|c|c|c|c|c|c|c|c|}
\hline ID & \begin{tabular}{|l|} 
Idade \\
$($ anos $)$
\end{tabular} & Sexo & Estado civil & $\begin{array}{l}\text { Anos } \\
\text { de } \\
\text { estudo }\end{array}$ & $\begin{array}{l}\text { Tipo de } \\
\text { lesão/impe- } \\
\text { dimento } \\
\text { corporal }\end{array}$ & $\begin{array}{l}\text { Aquisição da } \\
\text { deficiência }\end{array}$ & Ocupação & $\begin{array}{l}\text { Tipo de } \\
\text { trabalho }\end{array}$ \\
\hline E01 & 36 & M & $\begin{array}{l}\text { Casado/ com } \\
\text { companheira }\end{array}$ & $<9$ & $\begin{array}{l}\text { Física em } \\
\text { MMII }\end{array}$ & $\begin{array}{l}\text { Congênita/ na } \\
\text { infância }\end{array}$ & $\begin{array}{l}\text { Auxiliar administra- } \\
\text { tivo }\end{array}$ & Público \\
\hline E02 & 46 & $\mathrm{~F}$ & $\begin{array}{l}\text { Divorciada/ } \\
\text { desquitada }\end{array}$ & $\geq 16$ & $\begin{array}{l}\text { Física } \\
\text { múltipla/ } \\
\text { cadeirante }\end{array}$ & $\begin{array}{l}\text { Na idade } \\
\text { adulta }\end{array}$ & Escritora & Autônomo \\
\hline E03 & 24 & $\mathrm{~F}$ & Solteira & $12-15$ & Mental & $\begin{array}{l}\text { Congênita/ na } \\
\text { infância }\end{array}$ & $\begin{array}{c}\text { Embaladora em super- } \\
\text { mercado }\end{array}$ & Privado \\
\hline E04 & 59 & M & $\begin{array}{l}\text { Casado/ com } \\
\text { companheira }\end{array}$ & $\geq 16$ & Visual total & $\begin{array}{l}\text { Congênita/ na } \\
\text { infância }\end{array}$ & $\begin{array}{l}\text { Professor em escola } \\
\text { especializada e facul- } \\
\text { dade }\end{array}$ & $\begin{array}{l}\text { Público e } \\
\text { privado }\end{array}$ \\
\hline E05 & 38 & $\mathrm{~F}$ & $\begin{array}{l}\text { Divorciada/ } \\
\text { desquitada }\end{array}$ & $12-15$ & $\begin{array}{l}\text { Visual par- } \\
\quad \text { cial }\end{array}$ & $\begin{array}{l}\text { Congênita/ na } \\
\text { infância }\end{array}$ & $\begin{array}{c}\text { Chefe de serviço em } \\
\text { banco }\end{array}$ & Privado \\
\hline E06 & 42 & M & $\begin{array}{l}\text { Casado/ com } \\
\text { companheira }\end{array}$ & $\geq 16$ & Visual total & $\begin{array}{l}\text { Congênita/ na } \\
\text { infância }\end{array}$ & $\begin{array}{c}\text { Professor em escola } \\
\text { especializada }\end{array}$ & Público \\
\hline E07 & 45 & M & $\begin{array}{l}\text { Casado/ com } \\
\text { companheira }\end{array}$ & $\geq 16$ & $\begin{array}{l}\text { Auditiva } \\
\text { parcial }\end{array}$ & $\begin{array}{l}\text { Na idade } \\
\text { adulta }\end{array}$ & $\begin{array}{l}\text { Técnico de vigilância } \\
\text { sanitária }\end{array}$ & Público \\
\hline
\end{tabular}




\begin{tabular}{|c|c|c|c|c|c|c|c|c|}
\hline E08 & 30 & $\mathrm{~F}$ & Solteira & $\geq 16$ & $\begin{array}{l}\text { Física na } \\
\text { face }\end{array}$ & $\begin{array}{l}\text { Na idade } \\
\text { adulta }\end{array}$ & $\begin{array}{l}\text { Auxiliar administra- } \\
\text { tivo }\end{array}$ & Público \\
\hline E09 & 66 & $\mathrm{~F}$ & $\begin{array}{l}\text { Casada/ com } \\
\text { companheiro }\end{array}$ & $12-15$ & Visual total & $\begin{array}{c}\text { Congênita/ na } \\
\text { infância }\end{array}$ & $\begin{array}{l}\text { Revisora braile e pro- } \\
\text { fessora particular }\end{array}$ & $\begin{array}{l}\text { Público e } \\
\text { autônomo }\end{array}$ \\
\hline E10 & 54 & $\mathrm{M}$ & $\begin{array}{l}\text { Casado/ com } \\
\text { companheira }\end{array}$ & $\geq 16$ & Visual total & $\begin{array}{l}\text { Congênita/ na } \\
\text { infância }\end{array}$ & Bibliotecário braile & Público \\
\hline E11 & 37 & $\mathrm{~F}$ & $\begin{array}{l}\text { Divorciada/ } \\
\text { desquitada }\end{array}$ & $12-15$ & $\begin{array}{l}\text { Física em } \\
\text { MMII }\end{array}$ & $\begin{array}{l}\text { Na idade } \\
\text { adulta }\end{array}$ & $\begin{array}{l}\text { Assistente em imp- } \\
\text { rensa braile }\end{array}$ & Público \\
\hline E12 & 29 & $\mathrm{~F}$ & Solteira & $\geq 16$ & $\begin{array}{l}\text { Física em } \\
\text { MMII }\end{array}$ & $\begin{array}{c}\text { Congênita/ na } \\
\text { infância }\end{array}$ & $\begin{array}{l}\text { Professora do ensino } \\
\text { básico }\end{array}$ & Privado \\
\hline E13 & 42 & $\mathrm{~F}$ & $\begin{array}{l}\text { Casada/ com } \\
\text { companheiro }\end{array}$ & $\geq 16$ & $\begin{array}{l}\text { Física múlti- } \\
\text { pla }\end{array}$ & $\begin{array}{l}\text { Na idade } \\
\text { adulta }\end{array}$ & $\begin{array}{l}\text { Técnico de gestão } \\
\text { pública }\end{array}$ & Público \\
\hline E14 & 36 & $\mathrm{~F}$ & Solteira & $12-15$ & $\begin{array}{l}\text { Física em } \\
\text { MMII }\end{array}$ & $\begin{array}{l}\text { Congênita/ na } \\
\text { infância }\end{array}$ & Agente administrativo & Público \\
\hline E15 & 28 & $\mathrm{~F}$ & Solteira & $\geq 16$ & $\begin{array}{l}\text { Física em } \\
\text { MMII }\end{array}$ & $\begin{array}{c}\text { Congênita/ na } \\
\text { infância }\end{array}$ & $\begin{array}{l}\text { Dançarina, educadora } \\
\text { física e professora de } \\
\text { dança }\end{array}$ & Privado \\
\hline E16 & 44 & $\mathrm{~F}$ & Solteira & $<9$ & Mental & $\begin{array}{l}\text { Congênita/ na } \\
\text { infância }\end{array}$ & $\begin{array}{l}\text { Auxiliar em carrinho } \\
\text { de sanduíche }\end{array}$ & Privado \\
\hline E17 & 21 & $\mathrm{~F}$ & Solteira & $<9$ & Mental & $\begin{array}{c}\text { Congênita/ na } \\
\text { infância }\end{array}$ & $\begin{array}{c}\text { Embaladora em super- } \\
\text { mercado }\end{array}$ & Privado \\
\hline E18 & 59 & $\mathrm{M}$ & $\begin{array}{l}\text { Casado/ com } \\
\text { companheira }\end{array}$ & $<9$ & $\begin{array}{l}\text { Física em } \\
\text { MMII }\end{array}$ & $\begin{array}{l}\text { Na idade } \\
\text { adulta }\end{array}$ & Técnico de laboratório & Público \\
\hline E19 & 42 & $\mathrm{~F}$ & $\begin{array}{c}\text { Divorciada/ } \\
\text { desquitada }\end{array}$ & $12-15$ & $\begin{array}{l}\text { Física em } \\
\text { MMII }\end{array}$ & $\begin{array}{c}\text { Congênita/ na } \\
\text { infância }\end{array}$ & $\begin{array}{l}\text { Técnico em regulação } \\
\text { médica }\end{array}$ & Privado \\
\hline E20 & 42 & M & $\begin{array}{l}\text { Casado/ com } \\
\text { companheira }\end{array}$ & $9-11$ & Visual total & $\begin{array}{l}\text { Congênita/ na } \\
\text { infância }\end{array}$ & $\begin{array}{l}\text { Monitor de qualidade } \\
\text { em telefonia e técnico } \\
\text { de celulares }\end{array}$ & $\begin{array}{l}\text { Privado e } \\
\text { autônomo }\end{array}$ \\
\hline E21 & 44 & M & $\begin{array}{l}\text { Casado/ com } \\
\text { companheira }\end{array}$ & $12-15$ & Visual total & $\begin{array}{l}\text { Congênita/ na } \\
\text { infância }\end{array}$ & Ascensorista & Privado \\
\hline E22 & 26 & M & Solteiro & $<9$ & $\begin{array}{l}\text { Física em } \\
\text { MMII/ ca- } \\
\text { deirante }\end{array}$ & $\begin{array}{l}\text { Congênita/ na } \\
\text { infância }\end{array}$ & Vendedor ambulante & Autônomo \\
\hline E23 & 26 & M & $\begin{array}{l}\text { Casado/ com } \\
\text { companheira }\end{array}$ & $\geq 16$ & Visual total & $\begin{array}{c}\text { Congênita/ na } \\
\text { infância }\end{array}$ & Fisioterapeuta & Público \\
\hline E24 & 66 & M & Solteiro & $<9$ & $\begin{array}{c}\text { Auditiva } \\
\text { total }\end{array}$ & $\begin{array}{c}\text { Congênita/na } \\
\text { infância }\end{array}$ & $\begin{array}{l}\text { Professor de tipografia } \\
\text { e artesão }\end{array}$ & $\begin{array}{l}\text { Público e } \\
\text { autônomo }\end{array}$ \\
\hline E25 & 57 & M & $\begin{array}{l}\text { Casado/ com } \\
\text { companheira }\end{array}$ & $<9$ & $\begin{array}{l}\text { Auditiva } \\
\text { total }\end{array}$ & $\begin{array}{c}\text { Congênita/ na } \\
\text { infância }\end{array}$ & $\begin{array}{l}\text { Professor de marce- } \\
\text { naria e artesão }\end{array}$ & $\begin{array}{l}\text { Público e } \\
\text { autônomo }\end{array}$ \\
\hline E26 & 26 & M & Solteiro & $12-15$ & $\begin{array}{l}\text { Física e } \\
\text { mental }\end{array}$ & $\begin{array}{c}\text { Congênita/ na } \\
\text { infância }\end{array}$ & $\begin{array}{l}\text { Auxiliar de almoxari- } \\
\text { fado }\end{array}$ & Privado \\
\hline E27 & 26 & $\mathrm{M}$ & Solteiro & $12-15$ & Mental & $\begin{array}{c}\text { Congênita/ na } \\
\text { infância }\end{array}$ & Office-boy interno & Privado \\
\hline E28 & 29 & M & $\begin{array}{l}\text { Casado/ com } \\
\text { companheira }\end{array}$ & $\geq 16$ & $\begin{array}{c}\text { Auditiva } \\
\text { total }\end{array}$ & $\begin{array}{l}\text { Na idade } \\
\text { adulta }\end{array}$ & Contador & Privado \\
\hline E29 & 18 & $\mathrm{~F}$ & Solteira & $<9$ & $\begin{array}{l}\text { Auditiva } \\
\text { total }\end{array}$ & $\begin{array}{c}\text { Congênita/ na } \\
\text { infância }\end{array}$ & Digitadora & Privado \\
\hline E30 & 26 & $\mathrm{~F}$ & Solteira & $9-11$ & $\begin{array}{l}\text { Física em } \\
\text { MMSS }\end{array}$ & No trabalho & $\begin{array}{l}\text { Embaladora de peças } \\
\text { automotivas }\end{array}$ & Privado \\
\hline
\end{tabular}

ID: Identificação, M: masculino, F: feminino, MMII: membros inferiores, MMSS: membros superiores. 
A análise das entrevistas e observações resultou nos temas e subtemas a seguir.

\section{Centralidade do trabalho, mesmo que precário}

Trabalhar possibilita confrontar a realidade objetiva com suas regras, lógicas e desafios, com o mundo interno e subjetivo do trabalhador (Dejours, 1988; Lancman \& Sznelwar, 2004). Diferentes cenários sociais, históricos e econômicos indicam diferentes processos de produção de subjetividade e diferentes sujeitos trabalhadores, que se submetem e realizam ações conforme esse contexto (Elias \& Schroter, 1994; Ramminger \& Nardi, 2008).

Transformações recentes no modo de produção, na ordem social e institucional, no corpo de conhecimento e nas atitudes e valores contribuíram para a construção de uma sociedade mais rica e complexa, com novas necessidades e satisfações (Landes, 2005), e para um processo mais específico de precarização do emprego e intensificação do trabalho, caracterizado por maior dinamismo e flexibilidade organizacional (European Agency for Safety and Health at Work - EASHW, 2002). A classe trabalhadora contemporânea caracterizase pela diversidade, complexidade e expansão dos assalariados médios e do setor de serviços (Antunes, 2006; Ornellas \& Monteiro, 2006). O emprego tornou-se menos frequente e menos seguro (Bauman, 2001), havendo um crescimento do trabalho precário, informal e domiciliar, bem como a formação de um exército de reserva, em decorrência do desemprego estrutural de jovens e da dificuldade de requalificação e reingresso no mercado de trabalho (Antunes, 2006; Lancman \& Sznelwar, 2004).

Para a pessoa com deficiência, o desemprego e o subemprego são ainda mais frequentes, a despeito de toda uma legislação antidiscriminatória (Barnes, 2004). No estudo atual, as possibilidades de inserção da pessoa com deficiência no mercado de trabalho formal foram consideradas restritas devido à discriminação: "A gente não tem uma situação de pleno emprego. Então, o deficiente está concorrendo com duas frentes: com os outros candidatos, que são trabalhadores, e com a sua diferença, por ser uma pessoa com deficiência" (E04).

Esse cenário social gera instabilidade e perda do poder de barganha do trabalhador, o que pode levar à luta pelo acesso sem se questionar o caráter alienante do trabalho (Carmo, 1994; Lancman \& Sznelwar, 2004). O fato de estar trabalhando, independentemente de outros fatores, foi considerado pelos participantes deste estudo como um aspecto positivo: "Quer coisa melhor que trabalhar nos dias atuais? Nessa crise que estamos ai, estar trabalhando é uma coisa maravilhosa" (E06). Consequentemente, o indivíduo aceitou trabalhar em atividades que não correspondem ao seu anseio e/ou formação profissional, inclusive submetendo-se a condições de trabalho ruins, para não ficar desempregado. Para alguns dos entrevistados, ter um trabalho, qualquer que seja ele, é visto como uma oportunidade que não pode ser desperdiçada, principalmente devido ao fato de possuírem uma deficiência: "O mercado de trabalho para a pessoa deficiente visual é bem limitado porque não são tantas atividades compativeis. ... Como há pouca possibilidade, às vezes, surge uma que ela nem pensava e ela se agarra a ela" (E10).

Apesar de alguns autores ressaltarem que o trabalho deixou de ser o eixo seguro para autodefinições, identidades e projetos de vida (Bauman, 2001), os entrevistados deste estudo destacaram a centralidade do trabalho, apontado como uma das principais atividades da vida: "Para mim, [o trabalho] é tudo. É a minha vida. Sem ele, é meio complicado a própria existência da gente" (E10). Diversos estudos reportam o elevado valor moral do trabalho, pois a realização de tarefas socialmente reconhecidas constitui uma necessidade e uma expectativa social (Luckács, 1980; Organista, 2006; Ornellas \& Monteiro, 2006).

A importância do trabalho mostrouse relacionada, principalmente, ao seu caráter organizador da rotina, das relações sociais e dos projetos de vida. O trabalho foi considerado um determinante central na formação da identidade, conforme discutido por alguns autores (Aranha, 2007; Lancman \& Sznelwar, 2004; Oliveira, Araújo, \& Romagnoli, 2006): "Se eu falasse assim: 'eu não trabalho', ia ser como se uma parte de mim não existisse" (E13). São as relações cotidianas que permitem a construção da identidade pessoal e social das pessoas a partir de trocas materiais e afetivas, sendo o trabalho um lugar privilegiado para essas trocas na vida adulta (Lancman \& Sznelwar, 2004; Oliveira, Araújo, \& Romagnoli, 2006).

Em síntese, o trabalho foi apresentado como uma atividade social importante, organizadora da vida e estruturadora da identidade dos indivíduos, apesar de precário. O significado do trabalho ultrapassou seu caráter meramente técnico e financeiro, perpassando a estrutura socioeconômica, a cultura, os valores e a subjetividade dos trabalhadores. A participação da pessoa com deficiência no mundo do trabalho foi influenciada por esse contexto, que concorreu para vivências específicas de prazer e de sofrimento. 


\section{O trabalho como fonte de prazer}

Os entrevistados deste estudo destacaram diversos aspectos positivos do trabalho, relacionados a recompensas pessoais e à ampliação da rede social, que geram satisfação e sensações de bem-estar.

\section{Recompensas pessoais}

O sentido de utilidade proporcionado pelo trabalho e a possibilidade de fazer o que gosta foram fatores destacados como fonte de prazer: " $A$ satisfação no trabalho se concretiza na medida em que a gente se sente útil. Não é um trabalho que eu estou fazendo apenas porque existe um salário, uma remuneração, é porque ele traz satisfação" (E04). $\mathrm{O}$ sentido de utilidade, ou seja, a possibilidade de agir e reagir diante dos homens e da natureza, foi algo historicamente negado às pessoas com deficiência, e a busca desse sentido tornou-se uma meta importante para esses indivíduos (Carmo, 1994). Essas recompensas simbólicas contribuíram para a transformação do trabalho em uma experiência prazerosa.

\section{Ampliação da rede social}

O trabalho também propiciou a vinculação do indivíduo a um grupo social, como referido por alguns autores (Nohara, Acevedo, \& Fiammetti, 2009), tornando-se uma fonte de experiências e de relações humanas satisfatórias, e promovendo sentimentos de alegria, felicidade e bem-estar: "Você tem contato com os colegas no início, na chegada, na saida, e fora do emprego também. O contato com as pessoas que veem no prédio, que trabalham por aqui, essa é a melhor parte da coisa" (E21). Lukács (1980) aponta que o trabalho funda o ser social, sendo uma atividade permanente $\mathrm{e}$ inerente à própria existência humana, impulsionador da dinâmica da vida em sociedade. Estudos em psicodinâmica do trabalho também destacam o trabalho como o fator mais importante de produção de sentido para a integração social das pessoas (Lancman \& Sznelwar, 2004). Para o trabalhador com deficiência, especificamente, o trabalho possibilitou o desenvolvimento de habilidades, independência de familiares e/ou de caridade para sobreviver e para se envolver em outras situações da vida, como o lazer, o esporte e a socialização, o que gera sentimentos de prazer:

[Dá satisfação] saber que você recebe um salário todo mês, fruto do seu suor. Você não ficar dependendo de caridade de ninguém. Chego aqui e faço o trabalho. Meu trabalho é dividido normalmente com as outras pessoas que são normais, que não têm nenhum problema. Então, eu fico satisfeita com isso. (E11)
Autores destacam que o trabalho tem uma função especialmente positiva para minorias social e historicamente marginalizadas, pois representa a conquista de um direito, promovendo um sentimento de dignidade que permite à pessoa sair do lugar de vitimização (Oliveira, Araújo, \& Romagnoli, 2006; Schur, 2002).

Alguns entrevistados destacaram que o trabalho possibilitou a obtenção de recursos para a participação social e para a aquisição de bens, conectando-os a uma rede de produção, construção e convívio social: "Eu ficava mais parado em casa, não saía pra lugar nenhum. Agora eu saio pra todo canto, tenho o basquete, eu saio com os meninos de lá. É bom demais ter dinheiro assim" (E22). Antunes (2006) argumenta que, na sociedade contemporânea, há significativo domínio do capital na vida fora do trabalho, uma vez que as demais situações da vida acabam envolvendo o consumo e outras despesas. Trabalhar, portanto, possibilitou retorno financeiro capaz de dar suporte para a realização de outras atividades sociais.

\section{O trabalho como fonte de sofrimento}

Borsoi (2007) destaca que o trabalho atua como desencadeador, determinante ou constituinte do sofrimento psíquico. A forma como as pessoas se relacionam com ele pode ser fonte de prazer e bemestar, mas também fonte de frustração, desgaste, estresse, exclusão, inequidade e sofrimento, que afetam a saúde mental (Borsoi, 2007; Marchand, Demers, \& Durand, 2005; Takeda, 2005; Wieclaw, Agerbo, Mortensen, \& Bonde, 2006). Os fatores destacados pelos entrevistados como fonte de sofrimento psíquico foram agrupados em quatro categorias: imposições presentes no contexto organizacional; apropriações das exigências organizacionais; individualismo; desvalorização e falta de reconhecimento.

\section{Imposições presentes no contexto organizacional}

A necessidade de realizar muitas tarefas em curto período de tempo exige muita atenção e concentração do trabalhador, principalmente em atividades ligadas ao atendimento ao público, o que foi reportado como fonte de sofrimento: "Quando estou no atendimento, tenho que receber ligação, tenho que ser cordial, mas, ao mesmo tempo, tenho que ser rápida porque tenho que identificar situações, se é emergência ou uma orientação ... Ou você se equilibra, ou você está fora" (E19). Na atualidade, há uma reversão do trabalho ao trabalhador, em contraposição à separação concepção/ execução da época industrial. Entretanto, o aumento do volume e complexidade das tarefas exige do trabalhador o desenvolvimento de competências para 
lidar com eventos, se comunicar e realizar serviços seguindo ainda a lógica mercantil/industrial, o que gera sofrimento para o trabalhador (Salerno, 2001; Zarifian, 2001).

A rigidez da organização do trabalho pode dificultar o desenvolvimento de estratégias pelos trabalhadores para a execução das tarefas e, dessa forma, gerar sofrimento insuportável (Vilela \& Assunção, 2004). Esse conflito entre trabalho prescrito e real foi verificado nesta pesquisa, sendo referido como causador de sofrimento psíquico: "A gente tem que ter postura e ética profissional, o que, às vezes, é o que complica um pouco porque, dentro do funcionamento do serviço, você tem que dar uma extrapolada nela. E chega a ser revoltante em alguns momentos" (E19).

Essas imposições presentes no contexto organizacional afetam a pessoa com deficiência de forma especial. A cultura no ambiente de trabalho permanece ainda atrelada à perspectiva de que ela deve se adaptar ao ambiente, como se este fosse intocável, o que desencadeia uma mobilização muito mais expressiva de suas faculdades intelectuais, psicoafetivas e adaptativas: "Para eu ter chegado onde en estou agora, eu tive que me adaptar a muitas coisas. Adaptar, inclusive, a um mundo que não está preparado para me receber da maneira como eu sou hoje" (E13).

2. Apropriações das exigências presentes na organização

Como observado em outras situações de trabalho (Job, 2003), o estudo atual evidenciou a geração de uma demanda interna elevada, em termos de cobrança, que potencializa a pressão externa advinda do ambiente de trabalho: "Eu me sinto na obrigação de sobrepor, sempre dar um pouquinho a mais do que eu consigo" (E28). Na sociedade contemporânea, as pessoas são incentivadas a desenvolver autocontrole e independência, a competir e a distinguir-se pelas suas qualidades, esforços e realizações pessoais (Elias \& Schroter, 1994; Oliveira, 2006). No caso da pessoa com deficiência, essa questão é potencializada pela necessidade de muito esforço pessoal para atingir os mesmos níveis de produtividade dos demais trabalhadores: "Você tem que ter um diferencial, senão você não fica. E nós temos que ter um diferencial e meio, porque nós temos que nos superar" (E19).

A idade avançada e a doença associada também foram fatores referidos pelos entrevistados como responsáveis pelas limitações apresentadas. Amaral (1995) destaca a necessidade de não se negar a existência física, real, concreta de uma dada alteração corporal ou deficiência, o que não significa dizer que ela corresponda à totalidade do fenômeno, pois as limitações que uma pessoa apresenta não podem ser explicadas somente pelo biológico.

Quando os fatores idade e saúde vão pesando, você vai ficando meio pelo caminho. Você vê que já não dá mais pra correr muito. Não digo acomodar.. Você acha que podia tentar mais, mas seu organismo já não está querendo muito esforço, já não está dando conta, então você vai ficando um pouquinho para trás. Mas sempre com o intuito de estar, pelo menos, um passo atrás, mas sempre acompanhando o pessoal. (E18)

O medo de perder o emprego, as atitudes sociais negativas e os estereótipos levaram alguns entrevistados a minimizar ou esconder a realidade de sua deficiência, de forma a se adaptarem ao ambiente com a mínima interferência possível, o que pode ser observado na fala de um trabalhador com deficiência auditiva: "Eu tenho que dar o meu jeito. Eu tenho que ficar muito ligado. É muito cansativo. Eu tenho que ficar prestando muita atenção ... e eu procuro não parar a reunião por causa do meu problema" (E28). Foi observado, inclusive, que o atendimento às demandas de trabalho é, muitas vezes, alcançado à custa da ruína do próprio corpo e do estado de saúde da pessoa: "Eu estava com dores, mas não ficava reclamando, murmurando. Eu assumia paciente do mesmo jeito que qualquer outra colega minha" (E14).

\section{Individualismo}

Trabalhar não é somente produzir, mas também viver junto, o que pressupõe atenção e respeito, vontade de trabalhar e de superar, coletivamente, as contradições da organização do trabalho (Lancman \& Sznelwar, 2004). Para isso, seria necessário estabelecer relações de confiança entre os colegas. Mas o que foi relatado é que nem sempre isso acontece devido à ausência de afinidades, individualismo, competitividade, falta de comunicação e de cooperação, o que, por sua vez, foi considerado fonte de sofrimento: "As pessoas aqui não estão muito acostumadas a dividir nem compartilhar e, muito menos, trabalhar em equipe. Então, isso atrapalha um pouco. Às vezes, uma dificuldade que é minha, as pessoas expõem essa dificuldade ao invés de dividi-la comigo" (E23). Quando a pessoa se sente só, abandonada pelos demais, é muito mais difícil lidar com as adversidades do que quando se conta com a cumplicidade dos colegas. Para Dejours, as novas doenças do trabalho são, antes, doenças de solidão, devido à falta de solidariedade no trabalho (Lancman \& Sznelwar, 2004).

\section{Desvalorização e falta de reconhecimento}

Alguns entrevistados relataram que seu trabalho é pouco valorizado pela organização e pela sociedade 
em geral, e que a baixa remuneração é um dos fatores resultantes dessa desvalorização: "Eu sou um herói, porque sobreviver com o que eu ganho é dificil" (E01).

No caso específico da pessoa com deficiência, a desvalorização de sua capacidade para o trabalho provocou um direcionamento para a realização de tarefas simples, repetitivas, como se essa fosse a única alternativa para a inclusão. Essa subcontratação fez com que o trabalhador apresentasse dificuldades para se manter alerta durante o trabalho, tendo que introduzir tarefas secundárias em sua rotina para evitar o tédio (Conrad, 1997). De acordo com os entrevistados, a frustração diante da expectativa de realizar atividades mais estimulantes é um dos fatores responsáveis por transformar o trabalho em algo entediante. A obrigatoriedade de assegurar postos de trabalho para pessoa com deficiência por meio de cotas aumentou a oportunidade de emprego para esta parcela da população, mas a proposta de inclusão não foi efetivamente concretizada, ocorrendo apenas a inserção da pessoa com deficiência no mercado de trabalho: "eu observo que é mais a intenção de preencher a cota do que contar com aquela força de trabalho" (E28).

Trabalhar contra barreiras físicas, sociais e emocionais representa um peso imensurável para a pessoa com deficiência e pode gerar sensação de cansaço, desânimo e descontentamento com o trabalho: "O nosso serviço não é valorizado. Isso, realmente, deixa a gente mais pra baixo. Nós temos um compromisso, independente de qualquer coisa. Então, isso é um desgaste" (E19). Falhas no processo de educação profissional contribuem para a manutenção de um círculo vicioso: "Você não tem habilitação porque eles não habilitam, e eles não te aceitam porque você não é habilitado, mas ninguém habilita também não" (E06).

O trabalho também se desenvolve no mundo subjetivo, a partir do reconhecimento que se refere ao sentimento de ser aceito e admirado pela qualidade da tarefa concluída e de ter liberdade para expressar sua individualidade (Lancman \& Sznelwar, 2004; Ramminger \& Nardi, 2008). A falta de reconhecimento no trabalho foi um aspecto destacado pelos trabalhadores do estudo atual: "Você pode trabalhar, se esmerar, fazer tudo lindo e maravilhoso e ainda está pouco. Você não tem um elogio, um reforço" (E14). De acordo com Dejours, o não-reconhecimento do esforço do trabalhador e do custo desse esforço para a sua saúde é uma das principais fontes de sofrimento no trabalho. A transformação do prazer em sofrimento está diretamente relacionada ao olhar do outro e aos mecanismos de reconhecimento decorrentes desse olhar, fundamental para evitar uma possível alienação diante da falta de sentido do trabalho (Lancman \& Sznelwar, 2004).

Dejours argumenta que, quando não há reconhecimento no trabalho, o sofrimento pode contaminar o tempo do não-trabalho. $\mathrm{O}$ engajamento do indivíduo em outras atividades da vida, por sua vez, é importante para contrabalançar os efeitos nocivos da organização do trabalho (Dejours, 1988; Lancman \& Sznelwar, 2004). Atualmente, busca-se, inclusive, a conciliação entre um trabalho dotado de sentido e um tempo verdadeiramente livre e autônomo fora do trabalho para que o tempo excedente não seja utilizado para a produção exclusiva de valores de troca para o mercado e para a reprodução do capital (Antunes, 2006). No estudo atual, foi observado que o sofrimento gerado pelo trabalho atingiu outros espaços da vida cotidiana que também são considerados importantes, como o lazer, o descanso, o convívio familiar e a socialização, o que, de acordo com os entrevistados, prejudica a própria realização do trabalho: "Chego à noite em casa e não aguento fazer mais nada. Não consigo raciocinar, não consigo pensar. Às vezes, até assistir uma televisão é complicado porque o som da televisão te incomoda. Então, é cansativo demais" (E12).

\section{Resiliência}

As situações reais de trabalho são complexas e o prazer pode andar lado a lado com o sofrimento (Lancman \& Sznelwar, 2004). Os fatores destacados pelos entrevistados como geradores de prazer e sofrimento envolveram questões relacionadas à organização do trabalho e à deficiência, sendo verificada uma resposta pacífica e uma busca de sentido em meio à adversidade. Segundo os entrevistados, as limitações de atividade apresentadas influenciaram a forma de realizar o trabalho, mas não se converteram em obstáculos intransponíveis. Os trabalhadores com deficiência demonstraram capacidade de superar e de se fortalecer diante de situações extremamente desfavoráveis, ou seja, tornaram-se resilientes frente às exigências do mundo do trabalho, ao desejo de superação e à restrição de oportunidades: "A gente tem que estar sempre procurando ver, no meio da dificuldade, uma possibilidade de melhoria" (E18).

A resiliência é um fenômeno relacional, dinâmico e multidimensional, com nuances individuais, sociais e políticas (Barlach, LimongiFrança, \& Malvezzi, 2008; Infante, 2005). No estudo atual, a perseverança, a autoestima, o bom humor, a extroversão, a facilidade de comunicação e o suporte social apareceram como fatores de resiliência, ou seja, 
indicadores que contribuíram para o enfrentamento do risco representado pela situação adversa (Grotberg, 2005): "Depende muito da personalidade, do caráter da pessoa, de querer, de ter força de vontade e de não se importar" (E19). "As pessoas são fundamentais também, porque você pode estar querendo e todo mundo te jogar pra baixo" (E15).

O trabalho apresentou-se, portanto, como um elemento central e indispensável ao ser humano, sendo que a situação atual exige muita flexibilidade do trabalhador. A resiliência possibilitou aos entrevistados o ajuste e o alcance das expectativas sociais, uma vez que os trabalhadores utilizaram sua subjetividade de forma construtiva diante das inúmeras situações de tensão, pressão, ruptura e incertezas.

\section{Considerações finais}

A pessoa com deficiência foi inserida no mercado de trabalho em um momento histórico conturbado decorrente de profundas transformações no mundo do trabalho. O emprego estável, regulado e assalariado foi substituído pelo trabalho instável, escasso e precário, o que influenciou a forma de agir e pensar de toda a sociedade, gerando mais individualismo e novas vivências de prazer e sofrimento. Além de ter que lidar com todas as questões decorrentes dessas transformações, as vivências da pessoa com deficiência no trabalho apresentaram características específicas, relacionadas à forma como a categoria deficiência vem sendo historicamente construída. $\mathrm{O}$ prazer ganhou conotação especial, possibilitando a passagem de um lugar de vitimização para um lugar digno e socialmente reconhecido. Por outro lado, as cobranças em termos de desempenho da pessoa com deficiência acarretaram acentuados esforços de superação frente a uma realidade marcada pelo desemprego, subcontratação, desvalorização e falta de reconhecimento. Diante de todas as adversidades, o trabalhador com deficiência demonstrou utilizar sua subjetividade de forma construtiva. Trabalhar com uma deficiência revelou-se, portanto, uma experiência complexa que envolve a interação entre um corpo com lesões, a subjetividade, a organização do trabalho e a sociedade como um todo.

Aanálise das entrevistas realizadas com as pessoas com deficiência acerca de sua experiência de trabalho possibilitou a identificação de aspectos relacionados ao prazer e ao sofrimento que permaneciam ocultos e pouco explorados. Entender a influência da organização do trabalho na dimensão psíquica dos trabalhadores com deficiência é de fundamental importância para a compreensão do cenário atual relacionado à questão, para o direcionamento de futuras intervenções em situações de trabalho e para o aperfeiçoamento das abordagens relacionadas à funcionalidade e à incapacidade.

\section{Agradecimento}

Ao MCT/CNPQ pelo apoio financeiro.

\section{Referências}

Amaral, L. A. (1995). Conhecendo a deficiência: em companhia de Hércules. São Paulo: Robe Editorial.

Antunes, R. (2006). Os sentidos do trabalho: ensaio sobre a afirmação e a negação do trabalho. São Paulo: Boitempo.

Aranha, M. S. F. (1995). Integração social do deficiente: análise conceitual e metodológica. Temas em Psicologia, 3(2), 6370.

Aranha, M. S. F. (2007). Trabalho e emprego: instrumento de construção da identidade pessoal e social. São Paulo: SorriBrasil.

Bardin, L. (2008). Análise de conteúdo. Lisboa: Edições 70.

Barlach, L., Limongi-França, A. C., \& Malvezzi, S. (2008). O conceito de resiliência aplicado ao trabalho nas organizações. Interamerican Journal of Psychology, 42(1), 101-112.

Barnes, C. (2004). Independent living, politics and implications. Leeds: University of Leeds.

Bauman, Z. (2001). Trabalho. In Z. Bauman, Modernidade líquida (pp. 150-192). Rio de Janeiro: Jorge Zahar.

Borsoi, I. C. F. (2007). Da relação entre trabalho e saúde à relação entre trabalho e saúde mental. Psicologia \& Sociedade, 19(n. spe.), 103-111.

Carmo, A. A. (1994). Deficiência fisica: a sociedade brasileira cria, "recupera" e discrimina. Brasília: Secretaria de Desportos.

Conrad, P. (1997). It's boring: Notes on the meanings of boredom in everyday life. Qualitative Sociology, 20(4), 465475.

Dejours, C. (1988). A loucura do trabalho: estudo de psicopatologia do trabalho. São Paulo: Cortez-Obore.

Diniz, D. (2007). O que é deficiência. São Paulo: Brasiliense.

European Agency for Safety and Health at Work - EASHW. (2002). New forms of contractual relationships and the implications for occupational safety and health. Luxembourg: OOPEC.

Elias, N. \& Schroter, M. (1994). A sociedade dos individuos. Rio de Janeiro: J. Zahar.

Fontanella, B. J. B., Ricas, J., \& Turato, E. R. (2008). Amostragem por saturação em pesquisas qualitativas em saúde: contribuições teóricas. Cadernos de Saúde Pública, 24(1), 17-27.

Foucault, M. (2001). Os anormais. São Paulo: Martins Fontes.

Grotberg, E. H. (2005). Introdução: novas tendências em resiliência. In A. Melillo \& E. N. S. Ojeda (Orgs.), Resiliência: descobrindo as próprias fortalezas (pp.15-22). Porto Alegre: Artmed.

Infante, F. (2005). A resiliência como processo: uma revisão da literatura recente. In A. Melillo \& E. N. S. Ojeda (Orgs.), Resiliência: descobrindo as próprias fortalezas (pp. 23-38). Porto Alegre: Artmed. 
Instituto Brasileiro de Geografia e Estatística - IBGE. (2011). Censo Demográfico: Resultados preliminares da amostra. Acesso em 26 de novembro, 2011, em http:/www. censo2010.ibge.gov.br

Job, F. P. F. (2003). Os sentidos do trabalho e a importância da resiliência nas organizações. Tese de Doutorado, Escola de Administração de Empresas de São Paulo, Fundação Getúlio Vargas, São Paulo, SP.

Lancman, S. \& Sznelwar, L. I. (2004). Christophe Dejours: da psicopatologia à psicodinâmica do trabalho. Rio de Janeiro: Editora Fiocruz.

Landes, D. S. (2005). Prometeu desacorrentado. Rio de Janeiro: Editora Campus.

Lukács, G. (1980). The ontology of social being. London: Merlin Press.

Marchand, A., Demers, A., \& Durand, P. (2005). Does work really cause distress? The contribution of occupational structure and work organization to the experience of psychological distress. Social Science \& Medicine, 61(1), $1-14$.

Mendes, A. M. \& Tamayo, A. (2001). Valores organizacionais e prazer-sofrimento no trabalho. Psico-USF, 6(1), 39-46.

Nohara, J. J., Acevedo, C. R., \& Fiammetti, M. (2009). A vida no trabalho: as representações sociais das pessoas com deficiências. In M. N. Carvalho-Freitas \& A. L. Marques (Orgs.), O trabalho e as pessoas com deficiência: pesquisas, práticas e instrumentos de diagnóstico (pp. 71-88). Curitiba: Juruá.

Oliveira, A. V. (2006). Pós-modernidade e sofrimento psíquico: análise feita a partir de depoimentos de psicólogos clínicos. Dissertação de Mestrado, Pontifícia Universidade Católica de Minas Gerais, Belo Horizonte.

Oliveira, J. M., Araújo, J. N. G., \& Romagnoli, R. C. (2006). Dificuldades relativas à inclusão social das pessoas com deficiência no mercado de trabalho. Latin-American Journal of Fundamental Psychopathology, 6(1), 77-89.

Organista, J. H. C. (2006). O debate sobre a centralidade do trabalho. São Paulo: Expressão Popular.

Organização Mundial da Saúde - OMS. (2003). CIF: Classificação Internacional de Funcionalidade, Incapacidade e Saúde. São Paulo: Editora da USP.

Ornellas T. C. F. \& Monteiro, M. I. (2006). Aspectos históricos, culturais e sociais do trabalho. Revista Brasileira de Enfermagem, 59(4), 552-555.

Pereira, R. J. (2006). Anatomia da diferença: uma investigação teórico-descritiva da deficiência à luz do cotidiano. Tese de Doutorado, Escola Nacional de Saúde Pública Sérgio Arouca, Fundação Oswaldo Cruz, Rio de Janeiro, RJ.

QRS International. (2008). NVivo qualitative data analysis software (Versão 8.0) [programa de computador]. http:// www.qrsinternational.com

Ramminger, T. \& Nardi, H. C. (2008). Subjectivity and work: Some conceptual contributions from Michel Foucault. Interface (Botucatu), 12(25), 339-346.

Salerno, M. S. (2001). A seu serviço: interrogações sobre o conceito, os modelos de produção e o trabalho em atividades de serviços. In M. S. Salerno (Org.), Relação de serviço: produção e avaliação (pp. 11-22). São Paulo: Editora Senac.

Sampaio, R. F. \& Luz, M. T. (2009). Funcionalidade e incapacidade humana: explorando o escopo da classificação internacional da Organização Mundial da Saúde. Cadernos de Saúde Pública, 25(3), 475-483.
Sassaki, R. K. (1999). Inclusão: construindo uma sociedade para todos ( $3^{\mathrm{a}}$ ed.). Rio de Janeiro: WVA.

Schur, L. (2002). The difference a job makes: The effects of employment among people with disabilities. JEI, 36(2), 339348.

Takeda, F. (2005). The relationship of job type to Burnout in social workers at social welfare offices. Journal Occupational Health, 47, 119-125.

Turato, E. R. (2003). Tratado de metodologia da pesquisa clínico-qualitativa. Petrópolis, RJ: Vozes.

Vilela, L. V. O. \& Assunção, A. A. (2004). Os mecanismos de controle da atividade no setor de teleatendimento e as queixas de cansaço e esgotamento dos trabalhadores. Cadernos de Saúde Pública, 20(4), 1069-1078.

Wieclaw, J., Agerbo, E., Mortensen, P. B., \& Bonde, J. P. (2006). Risk of affective and stress related disorders among employees in human service professions. Occupational Environmental Medicine, 63, 314-319.

Zarifian, P. (2001). Das mutações do trabalho à competência. In P. Zarifian (Org.), Objetivo competência: por uma nova lógica (pp. 36-65). São Paulo: Editora Atlas.

Recebido em: 04/07/2011

Revisão em: 07/04/2012

Aceite em: 05/05/2012

Cecilia Martins Coelho é Fisioterapeuta, especialista em Ergonomia e mestre em Ciências da Reabilitação pela Universidade Federal de Minas Gerais. Trabalha na Secretaria de Estado de Saúde de Minas Gerais, com Vigilância em Saúde. E-mail: mcoelho@gmail.com

Rosana Ferreira Sampaio é Fisioterapeuta, doutora em Saúde Pública pela Universidad Autonoma de Barcelona e possui pós-doutorado pela Universidade do Estado do Rio de Janeiro. É professora associada e orientadora de mestrado/doutorado na Universidade Federal de Minas Gerais. Endereço: Programa de Pós-graduação em Ciências da Reabilitação, Escola de Educação Física, Fisioterapia e Terapia Ocupacional, Universidade Federal de Minas Gerais. Av. Antônio Carlos, 6.627, Campus Pampulha, Belo Horizonte/MG, CEP 31270-901. E-mail: rosana@netuno.lcc.ufmg.br

Marisa Cotta Mancini é Terapeuta Ocupacional, mestre em Ciências da Reabilitação pela University of Alberta, doutora em Ciência da Reabilitação pela Boston University e possui pós-doutorado pela University of Connecticut. É professora titular, orientadora de mestrado/doutorado e Pró-reitora Adjunta de Pesquisa da Universidade Federal de Minas Gerais. E-mail: mcmancini@pib.com.br

\section{Como citar:}

Coelho, C. M., Sampaio, R. F., \& Mancini, M. C. (2014). Trabalhadores com deficiência: vivências de prazer e sofrimento. Psicologia \& Sociedade, 26(1), 214-223. 